ISSN 1112-9867

http://www.jfas.info

\title{
SYNERGISTIC CO-CULTIVATION OF ACTIVATED SLUDGE AND MICROALGAE IN ENHANCING LIPID PRODUCTION AND N-LADEN WASTEWATER TREATMENT
}

\author{
W. H. Leong ${ }^{1}$, J. W. Lim ${ }^{1, *}$, Y. Uemura ${ }^{2}$, Y. C. Ho ${ }^{3}$ and M. S. Shaharun ${ }^{1}$ \\ ${ }^{1}$ Department of Fundamental and Applied Sciences, UniversitiTeknologi PETRONAS, 32610 \\ Seri Iskandar, Perak, Malaysia \\ ${ }^{2}$ Department of Chemical Engineering, UniversitiTeknologi PETRONAS, 32610 Seri \\ Iskandar, Perak, Malaysia \\ ${ }^{3}$ Department of Civil and Environmental Engineering, UniversitiTeknologi PETRONAS, \\ 32610 Seri Iskandar, Perak, Malaysia
}

Published online: 10 November 2017

\begin{abstract}
The influence of inoculation ratios of activated sludge and microalgae were investigated in this study in the aspects of biomass yield, lipid yield and total nitrogen (TN) removal efficiency. It was observed that mixed culture of activated sludge/microalgae with the ratio 1:1 and 1:0.75 achieved a maximum lipid production up to $0.144 \mathrm{~g} / \mathrm{L}$ and $0.133 \mathrm{~g} / \mathrm{L}$ as compared with microalgae culture alone, which was only $0.081 \mathrm{~g} / \mathrm{L}$. The highest total nitrogen $(\mathrm{TN})$ removal was observed with 1:1 and 1:0.75 ratios of activated sludge/microalgae cultures ranging from 96.3-96.9\% removal efficiency, which was an improvement of about $90 \%$ removal efficiency compared to the activated sludge culture $(6.25 \pm 0.08 \%)$.
\end{abstract}

Author Correspondence, e-mail: junwei.lim@utp.edu.my

doi: $\underline{\text { http://dx.doi.org/10.4314/jfas.v9i6s.50 }}$ 
The flocculation efficiency was generally improved in mixed cultures of activated sludge and microalgae in comparison with only activated sludge culture and microalgae culture alone.

Keywords: activated sludge; microalgae; co-cultivation; lipid; nitrogen removal.

\section{INTRODUCTION}

With the increasing trend of energy consumption, over-reliance on non-renewable energy sources of fossil fuels (coal, petroleum and gas) which contributes about $81 \%$ of the US energy demand in 2016 would soon exhaust our current reserve thus, not being able to meet the future consumption demands [1]. Besides that, the usage of fossil fuels has brought about environmental concerns particularly global warming due to the greenhouse gasses emitted during fossil fuel combustion. Therefore, alternative energy sources which are readily available, accessible and greener in nature are much needed in meet the future demands of energy requirements. As such, biofuels from lipid feedstock such as soybean, rapeseed, sunflower, palm oil, etc. served as potential alternative sources as they are sustainable and greener in nature. However, the usage of such edible feedstock will engender food versus energy crisis. With that, the search for more economical feedstock for biodiesel production has turned attention to various forms of waste alternative raw materials. Focusing on wastewater treatment plants, activated sludge, containing mainly microorganisms is a major waste byproduct of secondary treatment process. It is deemed that sludge production is a continuous process based on some generated statistics. In the European Union (EU), the estimated total sludge generation in 2020 is approximately 12.9 million tons of dry sludge per annum as compared with 10.0 million tons per annum in 2005 which recorded an increase of $30 \%$ [2]. Besides, the US Environmental Protection Agency (USEPA) estimated that US would generate about 7.6-8.2 million tons of dry sludge annually [3]. In addition to its availability in large quantities, researchers had also verified the possibility of biodiesel production from activated sludge. However, the main setback frequently highlighted in their reports was merely small quantity of lipid that could be harvested from activated sludge (< $10 \%$ of dry wt), leading to low biodiesel production $(<5 \%$ of dry wt) [4]. Other microbial species such as microalgae are generally touted to have higher growth tendencies coupled with its ability to accumulate large lipid content in their cells [5]. Therefore, co-cultivation of 
microorganisms and microalgae is expected to raise the lipid quantity in the activated sludge system.

Looking into organic nutrient removal in wastewater treatment processes, the typical secondary treatment system is usually poor in nutrient removal as excessively high nitrate levels tend to be found in the treated wastewater from conventional activated sludge process, thus posing health hazards unless being subjected to denitrification process which would further incur costs by supplementing carbon sources in denitrifying the remaining nitrate levels in the wastewater [6]. In recent years, integrating microalgae into wastewater treatment has gained interest due to ability of microalgae to biologically abate the organic nutrient sources found in domestic and industrial wastewater without the need of supplementing carbon sources compared to the conventional activated sludge process [7-8]. Besides that, the organic nutrients found in wastewater would induce rapid growth rate in microalgae which requires nitrogen and phosphorus sources as nutrient sources for growth would be able to produce useful biomass feedstock for biodiesel production which would have economic and environmental prospects in addition to reduce the nutrient concentrations in the treated wastewater to the discharged limits requirement [9]. Also, the necessity to setup bioreactor specifically for cultivation of only microalgae for biodiesel production can be avoided by using the activated sludge reactors in wastewater treatment plants, saving the footprint. Conclusively, the co-cultivation of microorganisms and microalgae in activated sludge system is anticipated to bring down the cost of biodiesel production in an environmentally friendly manner, besides promoting sustainable green technology and eco-technology of the nation.

\section{MATERIALS AND METHODS}

\subsection{Activated Sludge and Chlorella Vulgaris Cultures}

Samples of activated sludge obtained from the local wastewater treatment plant was initially inoculated in a sequencing batch reactor (SBR) in parallel with a cycle time of 24 hours in the following sequencing periods: instantaneous FILL, 0 hour; aerobic REACT, 10 hours; SETTLE, 1.5 hours; DRAW, 1 hour and IDLE, 11.5 hours. During each cycle, 14 liters of synthetic municipal wastewater (feed solution) was introduced into the reactor and the same volume of treated effluent was removed during the DRAW period. The sludge age was 
maintained at 40 days. The synthetic municipal wastewater composition is prepared by mixing the following components (in $\mathrm{mg} / \mathrm{L}$ ): sucrose (109), $\mathrm{FeCl}_{3} \cdot 6 \mathrm{H}_{2} \mathrm{O}$ (10), $\mathrm{CaCl}_{2}$ (42), $\left(\mathrm{NH}_{4}\right)_{2} \mathrm{SO}_{4}$ (226), $\mathrm{NaH}_{2} \mathrm{PO}_{4}$ (35), $\mathrm{Na}_{2} \mathrm{HPO}_{4}$ (180), $\mathrm{MgSO}_{4}$ (49) and $\mathrm{NaHCO}_{3}$ (354). Inoculation of the freshwater microalgae species, Chlorella vulgaris was done in a separate photobioreactor, continuously aerated with compressed air and illuminated with cool-white fluorescent light (light intensity of $60-70 \mu \mathrm{mol} \mathrm{m}^{-2} \mathrm{~s}^{-1}$ ) with the $\mathrm{pH}$ being maintained at 7.1.

\subsection{Co-Cultivation Setups}

Once the cultures were acclimated to the synthetic municipal wastewater (attaining steady growth in every cycle) different ratios of activated sludge and microalgae were prepared in determining the possibility of co-cultivating microorganisms (activated sludge) with microalgae. The activated sludge to microalgae ratios (activated sludge: microalgae) being investigated were 1:0 (100 mg: $0 \mathrm{mg})$ activated sludge only, 1:0.25 (100 mg: $25 \mathrm{mg})$, 1:0.5 (100 mg: $50 \mathrm{mg}), 1: 0.75$ (100 mg: $75 \mathrm{mg}), 1: 1$ (500 mg: $500 \mathrm{mg})$ and 0:1 (0 mg: $100 \mathrm{mg})$ microalgae only. Each of the different ratio parameters was cultivated in 1-liter conical flask containing $900 \mathrm{ml}$ of synthetic municipal wastewater prepared for inoculating activated sludge and microalgae cultures as the growth medium. All the six bioreactors were continuously aerated with compressed air and illuminated with cool-white fluorescent light (light intensity of $60-70 \mu \mathrm{mol} \mathrm{m} \mathrm{m}^{-2}$ ) with the $\mathrm{pH}$ being maintained at 7.1 throughout the study.

\subsection{Analysis of Biomass Concentrations}

The microbial biomass concentration $(\mathrm{g} / \mathrm{L})$ of each of the respective cultures was determined gravimetrically once the cultures had reached stationary growth phase. Approximately $10 \mathrm{ml}$ of sample was transferred into glass vial and washed twice with distilled water via centrifugation at 3,800 rpm for 20 minutes. The supernatant was decanted out and the remaining biomass sample was dried in the oven to the constant weight at $105^{\circ} \mathrm{C}$ before the dried biomass is weighed. Samplings were performed in duplicate.

\subsection{Determination of Total Nitrogen Concentrations and Removal Rates}

The ammonium-nitrogen $\left(\mathrm{NH}_{4}{ }^{+}-\mathrm{N}\right)$ and nitrate-nitrogen $\left(\mathrm{NO}_{3} \mathrm{~N}\right)$ concentrations were determined using the ammonia-selective electrode and nitrate electrode methods, whereas the nitrite-nitrogen $\left(\mathrm{NO}_{2}^{-}-\mathrm{N}\right)$ concentration was determined by colorimetric method. The determination of each respective nitrogen species was done following the Standard Methods 
[13]. All samplings were performed in duplicate.

\subsection{Determination of Flocculation Efficiency}

In determining the flocculation efficiency of the respective cultures, the cultures were stirred and the OD650 is measured immediately using spectrophotometer (Shimadzu UV-2600). The cultures were left undisturbed for a period of 20 minutes to allow the suspended solids or aggregates to settle. An aliquot of each sample was then obtained at a depth of $2.5 \mathrm{~cm}$ below the surface and the OD650 was re-measured. The flocculation efficiency was calculated based on the following Equation (1) [14].

Flocculation efficiency $(\%)=(1-\mathrm{A} / \mathrm{B}) \times 100$

A: OD650 of sample, B: OD650 of reference (control prior to settling period). Measurements of flocculation efficiency were determined during the initial and end of the batch culture experiments.

\subsection{Lipid extraction}

The microbial lipid content was performed and analyzed at the end of the batch culture experiments. The microbial cells of each different inoculation ratios of activated sludge/ microalgae were harvested by centrifugation and subjected to lipid extraction process using a mixed methanol-chloroform volume ratio of 2:1 [15]. The lipid was collected and the biomass residues left were subjected to repeated extraction twice using the same solvent. The crude lipid collected were measured gravimetrically. All samplings were performed in duplicate.

\section{RESULTS AND DISCUSSION}

\subsection{Effect of Activated Sludge/Microalgae Inoculation Ratios on the Biomass and Lipid Yield}

The biomass and lipid yield $(\mathrm{g} / \mathrm{L})$ obtained from the six different inoculation ratios of activated sludge/microalgae throughout the study were depicted in Table 1. The activated sludge maintained a biomass concentration of $0.10-0.13 \pm 0.01 \mathrm{~g} / \mathrm{L}$ throughout the study and this might be due to the exhaustion of carbon source in the culture medium. Activated sludge/microalgae ratio of 1:1 recorded the highest biomass yield which was $0.72 \pm 0.11 \mathrm{~g} / \mathrm{L}$ followed by 1:0.75 $(0.65 \pm 0.05 \mathrm{~g} / \mathrm{L}), 1: 0.50$ ratio $(0.57 \pm 0.05 \mathrm{~g} / \mathrm{L})$ and 1:0.25 ratio $(0.45 \pm 0.03$ $\mathrm{g} / \mathrm{L}$ ). These values recorded by the mixed cultures of activated sludge and microalgae were 
relatively higher than microalgae culture alone which recorded a maximum biomass concentration of $0.26 \pm 0.05 \mathrm{~g} / \mathrm{L}$ only. It was surmised that the spurt of maximum biomass concentration of the mixed cultures was mainly due to effective nutrient assimilation particularly nitrates into the microalgae biomass as compared to the microalgae culture alone. The presence of activated sludge (nitrifying bacterium) in the mixed cultures nitrified the ammonium-nitrogen species in the culture medium into nitrate-nitrogen species which would be more favourable for microalge growth compared to the other nitrogen sources. Similar findings also hypothesized that the microalgae, Chlorella vulgaris, preferred nitrate-nitrogen source over other nitrogen sources such as ammonium, nitrite or urea for growth [10].

As for the lipid yield of the various co-cultivation systems, it was determined that higher biomass concentration would yield higher lipid production. As expected, the mixed cultures of activated sludge and microalgae recorded higher lipid yield due to higher biomass yield obtained in which the activated sludge/microalgae ratio of 1:1 and 1:0.75 recorded the highest lipid yield of $0.144 \pm 0.004 \mathrm{~g} / \mathrm{L}$ and $0.133 \pm 0.005 \mathrm{~g} / \mathrm{L}$ respectively followed by the 1:0.50 ratio $(0.105 \pm 0.004 \mathrm{~g} / \mathrm{L})$ and 1:0.25 $(0.084 \pm 0.003 \mathrm{~g} / \mathrm{L})$ when compared to the microalgae culture $(0.081 \pm 0.005 \mathrm{~g} / \mathrm{L})$ and activated sludge culture alone $(0.01 \pm 0.001 \mathrm{~g} / \mathrm{L})$. This implied that the co-cultivation of activated sludge and microalgae cultures (algal-bacterial culture) would be able to enhance the overall biomass and lipid production which would be beneficial as biodiesel production feedstock compared to microalgae culture alone.

Table 1. The biomass and lipid yield in various co-cultivation systems at the end of batch culture experiments

\begin{tabular}{ccc}
\hline $\begin{array}{c}\text { Inoculation Ratio of Activated } \\
\text { Sludge/Microalgae (AS:MA) }\end{array}$ & $\begin{array}{c}\text { Biomass } \\
\text { Yield (g/L) }\end{array}$ & $\begin{array}{c}\text { Lipid } \\
\text { Yield (g/L) }\end{array}$ \\
\hline AS:MA of 1:0.25 & $0.45 \pm 0.03$ & $0.084 \pm 0.003$ \\
AS:MA of 1:0.50 & $0.57 \pm 0.05$ & $0.105 \pm 0.004$ \\
AS:MA of 1:0.75 & $0.65 \pm 0.05$ & $0.133 \pm 0.005$ \\
AS:MA of 1:1 & $0.72 \pm 0.11$ & $0.144 \pm 0.004$ \\
Activated sludge & $0.13 \pm 0.01$ & $0.010 \pm 0.001$ \\
Microalgae & $0.26 \pm 0.05$ & $0.081 \pm 0.005$ \\
\hline
\end{tabular}




\subsection{Effect of Activated Sludge/Microalgae Inoculation Ratios on the Total Nitrogen}

\section{Removal Efficiency}

As shown in Fig. 1, the highest total nitrogen removal was found in the reactor inoculated with activated sludge/microalgae ratio of $1: 1$ and $1: 0.75$ with $96.9 \pm 0.00 \%$ and $96.3 \pm 0.31 \%$ removal efficiencies respectively followed by microalgae culture only $(87.7 \pm 0.31 \%), 1: 0.5$ $(82.0 \pm 0.34 \%), 1: 0.25(53.8 \pm 0.36 \%)$ and lastly activated sludge culture only $(6.3 \pm 0.08 \%)$. These results indicated that mixed cultures of activated sludge/microalgae had an significant influence in efficiently removing the organic nutrients particularly the nitrogen species without any supplementation of carbon sources due to nitrogen assimilation into the microalgae biomass as compared to activated sludge culture alone which would need additional carbon sources to support the denitrification process under anaerobic conditions in further removing the remaining organic nutrients particularly nitrates, $\mathrm{NO}_{3}{ }^{-}$in the typical wastewater medium.

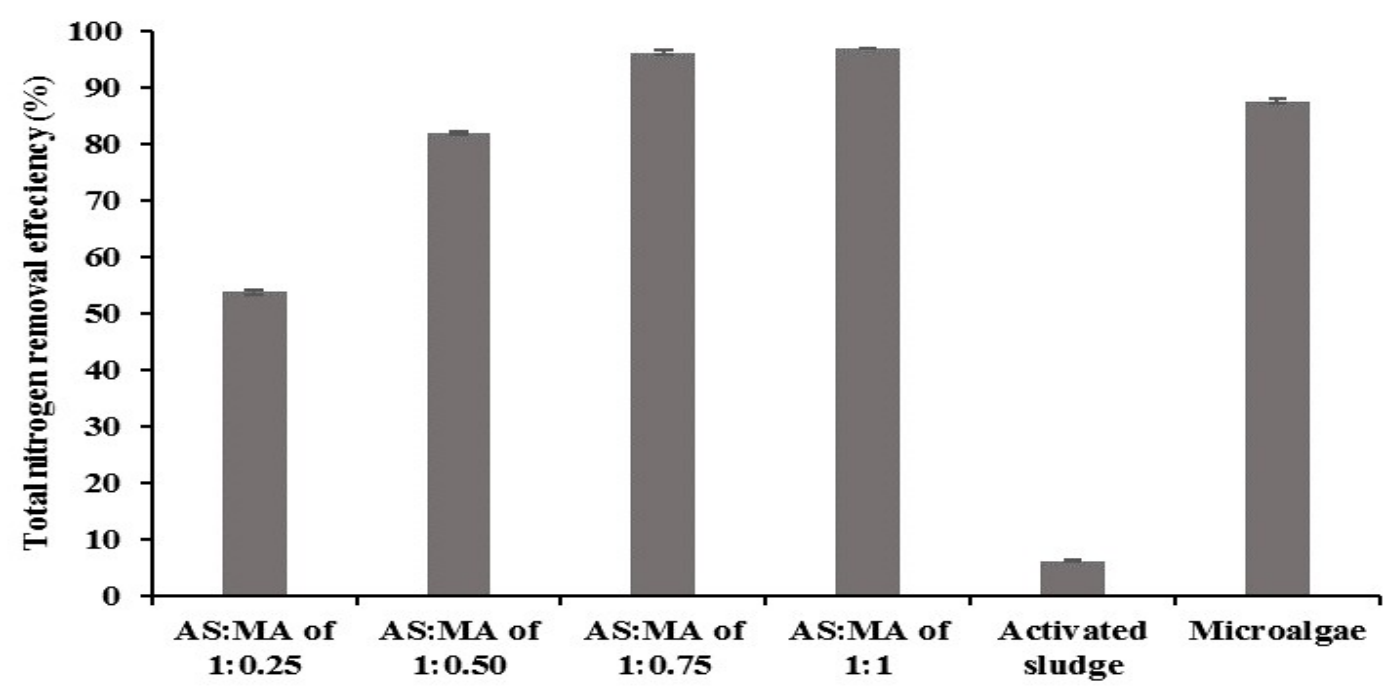

Fig.1. The total nitrogen removal efficiency in various co-cultivation systems at the end of batch culture experiments

\subsection{Effect of Activated Sludge/Microalgae Inoculation Ratios on the Flocculation}

\section{Efficiency}

It was observed that the four mixed cultures of activated sludge and microalgae had improved flocculation efficiency when compared to the control tests alone (activated sludge only and microalgae only). The highest increase in flocculation efficiency was observed in 1:0.50 ratio culture $(12.21 \%)$ followed by 1:0.75 ratio culture $(11.11 \%)$ then 1:0.25 ratio culture $(5.06 \%)$ and finally $1: 1$ ratio culture $(4.03 \%)$. Both the control tests experienced a decrease in flocculation efficiency in which the activated sludge culture recorded a decrease of $8.24 \%$ 
whereas there was a decrease in $4.53 \%$ in microalgae culture. It could be surmised that inoculating activated sludge into microalgae cultures generally increase the flocculation efficiency thus, fasten the natural settling time of microalgae cultures for the ease of harvesting process. Similar results were also obtained in strengthening the hypothesis whereby activated sludge could enhance the biomass settleability of algae biomass [11], which was surmised to be influenced by cell surface characteristics of algae in addition to the extra-cellular polymeric substances in enhancing the bio-flocculation process [12].

\section{CONCLUSION}

The results in this study showed that mixed culture of activated sludge/microalgae was feasible to be done in further enhancing biomass and lipid production. It was determined that mixed culture of activated sludge/microalgae with the ratio 1:1 and 1:0.75 achieved a maximum lipid production up to $0.144 \pm 0.004 \mathrm{~g} / \mathrm{L}$ as compared with the microalgae culture alone which was only $0.081 \pm 0.005 \mathrm{~g} / \mathrm{L}$. The highest total nitrogen removal was observed with 1:1 and 1:0.75 (activated sludge/microalgae) cultures ranging from 96.3-96.9\% removal efficiency which was an improvement of about $90 \%$ removal efficiency compared to the activated sludge culture. The flocculation efficiency was improved in mixed cultures of activated sludge and microalgae in comparison with only activated sludge culture and microalgae culture alone which experienced a decrease instead. This synergistic approach in utilizing both activated sludge and microalgae offers advantages in economic and environmental perspectives, especially when viewed in nutrient removal efficiency for potential wastewater treatment contributing to sustainability in the long-term process.

\section{ACKNOWLEDGEMENTS}

The financial support from Short Term Internal Research Funding (STIRF) with Ref: 0153AA-D80 granted by UniversitiTeknologi PETRONAS is greatly acknowledged.

\section{REFERENCES}

[1] U.S. Department of Energy.Today in energy-U.S. energy consumption rose slightly in 2016 despite a significant decline in coal use. 2017, 
https://www.eia.gov/todayinenergy/detail.php?id=30652

[2] Olkiewicz M, Fortuny A, Stüber F, Fabregat A, Font J, Bengoa C. Evaluation of different sludges from WWTP as a potential source for biodiesel production. Procedia Engineering, 2012, 42:634-643

[3] Mondala AH, Hernandez R, French T, McFarland L, Santo D JW, Meckes M, Ryu H, Iker B. Enhanced lipid and biodiesel production from glucose-fed activated sludge: Kinetics and microbial community analysis. AIChE Journal, 2012, 58(4):1279-1290

[4] Kargbo DM. Biodiesel production from municipal sewage sludges. Energy and Fuels, 2010, 24(5):2791-2794

[5] Lam MK, Lee K T. Microalgae biofuels: A critical review of issues, problems and the way forward. Biotechnology Advances, 2012, 30(3):673-690

[6] Leverenz HL, Haunschild K, Hopes G, Tchobanoglous G, Darby JL. Anoxic treatment wetlands for denitrification. Ecological Engineering, 2010, 36(11):1544-1551

[7] Li Y, Zhou W, Hu B, Min M, Chen P, Ruan RR. Integration of algae cultivation as biodiesel production feedstock with municipal wastewater treatment: strains screening and significance evaluation of environmental factors. Bioresource Technology, 2011, 102(23):10861-10867

[8] Nurdogan Y, Oswald WJ. Enhanced nutrient removal in high-rate ponds. Water Science and Technology, 1995, 31(12):33-43

[9] Clarens AF, Resurreccion EP, White MA, Colosi LM. Environmental life cycle comparison of algae to other bioenergy feedstocks. Environmental Science and Technology, 2010, 44(5):1813-1819

[10] Podevin M, De Francisci D, Holdt SL, Angelidaki I. Effect of nitrogen source and acclimatization on specific growth rates of microalgae determined by a high-throughput in vivo microplateautofluorescence method. Journal of Applied Phycology, 2015, 27(4):1415-1423

[11] Su Y, Mennerich A, Urban B. Synergistic cooperation between wastewater-born algae and activated sludge for wastewater treatment: Influence of algae and sludge inoculation ratios. Bioresource Technology, 2012, 105:67-73

[12] Gutzeit G, Lorch D, Weber A, Engels M, Neis U. Bioflocculent algal-bacterial biomass 
improves low-cost wastewater treatment. Water Science and Technology, 2005, 52(12):9-18

[13] American Public Health Association, American Water Works Association and Water Environmental Federation. Standard methods for the examination of water and wastewater.Washington DC: American Public Health Association (APHA), 2017

[14]Oh HM, Lee SJ, Park MH, Kim HS, Kim HC, Yoon JH, Kwon GS, Yoon BD. Harvesting of Chlorella vulgaris using a bioflocculant from Paenibacillus sp. AM49. Biotechnology Letters, 2001, 23(15):1229-1234

[15] Bligh EG, Dyer WJ. A rapid method of total lipid extraction and purification. Canadian Journal of Biochemistry and Physiology, 1959, 37(8):911-917

\section{How to cite this article:}

Leong W H, Lim W J, Uemura Y, Ho Y C, Shaharun M S. Synergistic co-cultivation of activated sludge and microalgae in enhancing lipid production and n-laden wastewater treatment. J. Fundam. Appl. Sci., 2017, 9(6S), 651-660. 